\section{EDITORIAL INTELIGÊNCIA HUMANA: CONTRIBUIÇÕES LUSO-BRASILEIRAS}

\author{
Este número é dedicado ao Professor \\ Franco Lo Presti Seminerio, um pes- \\ quisador do mais alto gabarito, além \\ de inovador e um grande promotor \\ da Pós-Graduação no Brasil e res- \\ ponsável pela editoração da Revista \\ Arquivos Brasileiros de Psicologia, a \\ mais antiga da América Latina
}

Pensar a questão da inteligência humana, embora intrigante, não é tarefa fácil e a ser concluída na atualidade. As histórias deste conceito e do próprio desenvolvimento humano atestam a complexidade do tema, sua polêmica intrínseca e, não menos, sua atualidade em termos de desafio à investigação científica. Compartilhamos esta pretensão na atual proposta de um número específico da revista "Paidéia" para colocar em foco o tema. Instigamos pesquisadores brasileiros e portugueses a apresentarem suas construções teóricas e empíricas, como um novo ponto de partida para estimular reflexões e o intercâmbio científico nesta área, almejando reativar o debate e a análise crítica sobre as diferentes formas de abordagens da inteligência.

A proposta foi amavelmente recebida pela comunidade científica portuguesa e brasileira, resultando em onze profícuos artigos presentemente trazidos a público. As diversidades de enfoques e de estudos, tanto teóricos quanto empíricos, reafirmam a riqueza da temática, instigadora humana há séculos. Certamente, organizar e apresentar esta variabilidade analítica da inteligência, jamais resolvida, não resultaria em perfeita harmonia conceitual e técnica.

Porém, o resultado foi bastante satisfatório $\mathrm{e}$ provocante: iniciamos apresentando artigos teóricos sobre a inteligência, focalizando desde elementos históricos à metodologia da investigação científica do tema, engajando-os na realidade sócio-cultural de nosso cotidiano ocidental. A seguir, apresentamos exaustivos trabalhos sobre algumas concepções de inteligência: a fluida e a emocional, com seus respectivos componentes conceituais e científicos.
Focalizamos, a seguir, o contexto escolar, tanto do ponto de vista teórico (teorias implícitas da inteligência), quanto numa abordagem clínica das dificuldades de aprendizagem, objetivando oferecer subsídios práticos à prática profissional neste campo de aplicação da Psicologia, focalizando os contextos português e brasileiro e as relações eventuais da inteligência com a avaliação neuropsicológica. Retomamos novamente o desafio do novo e da busca do aprimoramento compreensivo dos estilos cognitivos, focalizando estratégias conceituais de aprendizagem associadas ao universo computacional. Por fim, fechamos este número da revista propondo uma reflexão sobre mitos e fatos a respeito da inteligência no processo do envelhecimento, disparando revisão de estereótipos analíticos sobre o tema, sempre perigoso à adequada compreensão dos indivíduos. Abordamos ainda uma visão panorâmica do tema para ilustrar a história desse dinâmico e polêmico potencial humano.

Encerramos este número com uma vivência de gratidão aos colaboradores que prontamente atenderam ao desafio proposto, apresentando suas perspectivas científicas relativas à inteligência humana. Fazern parte desse volume os pesquisadores: Alexandre Sonntag, CRT Brasil Telecom; Antonio Roazzi, UFPE; Araguacy Brazil Viana, UFSCar; Bruno Campello de Souza, UFPE; Carmen E. FloresMendoza, UFMG; Daniel K. de A. Corrêa, UNISINOS; Daniela Andrea de Oliveira, UFSCar,Eduardo K. Diehl, UNISINOS; Elizabeth do Nascimento, UFMG; Franco Lo Presti Seminério, UFRJ; Ivana Regina Panosso, UFSCar; João C. Alchieri, UNISINOS; José P. de Oliveira, UFRGS; Juarez Sagebin, CRT Brasil Telecom,; Leandro S. Almeida, Univ. Minho; Luísa Faria, Univ. Porto; Marcus L. L. Barbosa, UNISINOS; Maria Aparecida Paiva Franco, UFSCar; Maria José Miranda, Univ. Lisboa; Mario Rodrigues Simões, Univ. Coimbra; Maritânia Molinari, UNISINOS; Milton J. P. Madeira, UNISINOS; Paulo César Gomes de Borba, UNISINOS; Paulo R. Mendel, CRT Brasil Telecom; Regina Verdin, UNISINOS; Reinier Johannes Antonius Rozestraten, U.C. Dom Bosco; Renata Zanella, CRT Brasil Telecom; Ricardo Primi, Univ. São Francisco; Ricardo Wainer, UNISINOS; Richard D. Roberts, Univ. Sidney; Rosa M. ViccariUFRGS; 
Simone B. Charczuk, UNISINOS; Sonia Regina Pasian, USP-RP; Susi Lippi Marques, UFSCar.

Há uma sensação de "dever cumprido"; foi proposto um desafio aos professores de Psicologia: repensar de forma inteligente, reflexiva, fluida e criativa a investigação sobre o conhecimento das potencialidades humanas, suas riquezas e suas misérias. Resta-nos manter a esperança e o estímulo por soluções criativas para alguns dos eternos (talvez) dilemas da busca de compreensão do ser humano: sua riqueza intelectual. Queremos especialmente agradecer aos editores da revista Paidéia: Dra. Zélia Maria Mendes Biasoli Alves e Eucia Beatriz Lopes Petean por terem prontamente acolhido a idéia da publicação deste número especial nesta revista dedicado ao tema Inteligência. Devemos também agradecer às nossas imprescindíveis secretárias Denise Aparecida Jardim Cremonezi e Regina Teles Gonçalves pela dedicação e esforços na revisão e organização final dos diferentes artigos que compõem este número especial. Elas sem dúvida alguma facilitaram e tornaram mais suave a nossa tarefa de organização.

A todos, autores e colaboradores, a nossa gratidão e reconhecimento.

Sonia Regina Pasian

José Aparecido da Silva 